\title{
Carta del editor
}

Cerca ya de entrar en la línea recta para que Meridional. Revista Chilena de Estudios Latinoamericanos cumpla una década de existencia, incorporaremos a cada edición una carta del editor. Esta será una forma más de fortalecer nuesta revista como un espacio de reflexión y comunicación de la vida de la institución que la edita: el Centro de Estudios Culturales Latinoamericanos (CECLA), de la Facultad de Filosofía y Humanidades de la Universidad de Chile.

Meridional nació como un proyecto que aspiraba a dar espacio a investigaciones involucradas en la tarea de comprender América Latina y toda su rica historia y cultura más allá de los compartimientos disciplinares y nacionales. Abierta a autores e investigadores del espacio local y global y al diálogo académico en castellano, francés, portugués e inglés, Meridional ha logrado consolidar una propuesta interdisciplinar sobre América Latina. Los esfuerzos del CeCla y de los profesores que han ejercido la tarea de editor o editora general, así como del director de la revista, el profesor Grínor Rojo, han sido fundamentales en esta tarea. No menor ha sido el apoyo que los estudiantes de los programas de Magíster y Doctorado en Estudios Latinoamericanos, impartidos por el CeCla, han brindado al desarrollo de la revista, en especial el de quienes en su momento se comprometieron con tareas de mediano plazo.

La propuesta de Meridional ha sido en forma consistente la de una ciencia abierta y desde el sur; es decir, una producción científica en humanidades con altos estándares académicos y, al mismo tiempo, con una vocación de reflexión crítica y de responsabilidad social en la difusión del conocimiento. Nuestra revista ha logrado proponer temas a través de la propuesta de dossiers temáticos $\mathrm{y}$, dentro de nuestras 
secciones habituales en cada número, abrir espacios de mayor libertad formal y diversidad a través de la sección "Notas", en la que publicamos entrevistas, testimonios, transcripciones, ensayos breves y otras formas de comunicación académica. Así, la vocación de Meridional - diversidad, excelencia académica, reflexión crítica sobre América Latina - ha logrado concretar en buena medida la propuesta del CECla como espacio de formación académica de posgrado y centro de estudios. Son ya dieciséis ediciones y esperamos que Meridional siga fortaleciendo su propuesta, sus procesos y contribuya cada vez más y mejor al conocimiento de América Latina.

Hoy son tiempos que llaman a reflexión. Empujados por la inminencia de la tragedia sanitaria que trajo la pandemia en el ańo 2020, la vida académica se ha visto transformada en sus prácticas y llevada a cuestionarse profundamente. Si bien Meridional es una revista académica, su temática está absolutamente implicada en la crítica reflexiva del presente. De ello dan cuenta sus dossiers sobre racismos en el Caribe, comunicación audiovisual en la era digital, culturas policiales, Brasil, los años sesenta en América Latina, entre otros. El presente nos asedia y estos tiempos han significado desafíos para todos, así como no poco dolor y tragedia en una región en la que el COVID-19 ha significado miles de muertes y verdaderas catástrofes sociales cuyos efectos aún no comprendemos del todo.

En este número, traemos una propuesta sobre intelectuales afrodescendientes en la región, un tema que nos enorgullecemos de presentar, valorar y destacar, ya que pone una atención diferente sobre la vida y producción cultural de esta parte importantísima de las identidades culturales latinoamericanas.

Seguimos invitando a investigadores e investigadoras a proponer dossiers, publicar, comentar, difundir y a usar libre y responsablemente -citando autores y fuentes-, las propuestas de Meridional, que se encuentran disponibles sin costo económico.

Marcelo Sánchez Delgado

Editor general revistameridional@gmail.com Marzo de 2021 